\title{
Constitutive Activation and Accelerated Maturation of Peripheral Blood T Cells in Healthy Adults in Burkina Faso Compared to Germany: The Case of Malaria?
}

\author{
F. Tiba1 , F. Nauwelaers², L. Sangare ${ }^{3}$, B. Coulibaly ${ }^{4}$, V. Mrosek¹, H.-G. Kräusslich¹, T. Böhler ${ }^{1}$ \\ ${ }^{1}$ Department of Infectious Diseases, Virology, University of Heidelberg, INF324, Heidelberg, Germany \\ ${ }^{2} \mathrm{BD}$ Biosciences, Erembodegem, Belgium \\ ${ }^{3}$ University Hospital Ouagadougou, Ouagadougou, Burkina Faso \\ ${ }^{4}$ Centre de Recherche en Sante de Nouna, Nouna, Burkina Faso
}

\begin{abstract}
Objective: It is not exactly known how frequent exposure to Plasmodium falciparum shapes the peripheral blood T-cell population in healthy West Africans. Methods: The frequency of peripheral blood $\mathrm{CD}^{+}$ lymphocytes responding to Plasmodium falciparum merozoite surface protein 1 (PfMSP-1) by production of interferon-gamma (IFN- $\gamma$ ), interleukin-2 (IL-2) or tumor necrosis factor-alpha (TNF- $\alpha$ ) was determined using a commercially available flow cytometric activation assay (FastImmune) in 17 healthy adults in Nouna, Burkina Faso. T-cell activation and maturation in peripheral blood of healthy adults in Burkina Faso $(n=40)$ and Germany $(n=20)$ were compared using immunophenotyping and three-colour flow cytometry. Results: Significant numbers of PfMSP-1 -specific $\mathrm{CD}^{+}{ }^{+}$lymphocytes producing IFN- $\gamma$, IL- 2 and/or TNF- $\alpha$ were detected in 14 healthy adults in Nouna. Cytokine profiles showed predominant production of IFN- $\gamma$ and TNF- $\alpha$. Compared to Germans, Burkinabé showed markedly lower proportions of $\mathrm{CCR}^{+}$ $\mathrm{CD}^{2} 5 \mathrm{RA}^{+}$naïve $\mathrm{CD}^{+}$cells and slightly higher frequencies of $\mathrm{CD}^{+} 5^{+} \mathrm{CD} 4^{+}$T-cells and of $\mathrm{CD}^{+} 8^{+}$ CD $8^{+}$T-cells. The median antibody-binding capacity of $\mathrm{CD} 95^{\mathrm{dim}} \mathrm{CD} 4^{+} \mathrm{T}$-cells in Burkinabé was more than twice the value observed in Germans (263 vs. 108 binding sites per cell, $\mathrm{p}<0.0001)$.

Conclusions: We hypothesize that an IFN- $\gamma$-induced increase in the expression level of CD95 on CD4 ${ }^{+}$ lymphocytes may lower the activation threshold of resting naïve $\mathrm{CD}^{+}{ }^{+} \mathrm{T}$-cells in healthy adults living in Burkina Faso. Bystander activation of these cells deserves further study as a molecular mechanism linking strong IFN- $\gamma$ responses against Plasmodium falciparum to decreased susceptibility to parasitemia observed in specific ethnic groups in West Africa.
\end{abstract}

Key words: flow cytometry; malaria; PfMSP-1; interferon gamma; CD95; CD45RA; CCR7; CD38

\section{INTRODUCTION}

Compared to Europeans, Africans frequently show signs of chronic immune activation of peripheral blood T-cells (Clerici et al. 2000). Recently, we assessed the distribution of T-cell maturation phenotypes in a population living in Nouna, rural Burkina Faso (Böhler et al. 2007) and observed significantly lower proportions of CD45RA bright CCR7pos naïve Tcells in healthy adults compared to published data from France (Saule et al. 2006). Such a skewed distribution of T-cell maturation phenotypes may be a consequence of chronic immune activation. Exposure to Plasmodium falciparum, the causative agent of malaria in that area, may be a driving force behind chronic immune activation. However, the ability of the parasite to induce long-lasting $\mathrm{T}$-cell immunity has long been questioned (Achtman AH et al. 2005, Struick and Riley, 2004). We therefore screened the population in Nouna during the dry season for the presence of peripheral blood T-cells specifically recognizing Plasmodium falciparum merozoite surface protein-1 ( PfMSP1), a surface protein expressed during the parasite's blood stage (Holder AA, 1988).

The immune response against Plasmodium falciparum blood-stage components is centrally mediated by interferon-gamma ( IFN- $\gamma$ ), which is produced predominantly by $\mathrm{CD}^{+}{ }^{+}$effector memory T-cells (McCall and Sauerwein, 2010). Antigen-dependent release of IFN- $\gamma$ has been shown to up-regulate the Fas-receptor (CD95) on bystander cells (Müllbacher et al. 2002). CD95-expression on human $\mathrm{CD}^{+}{ }^{+} \mathrm{T}$-cells was characterized by a bimodal distribution showing two peaks, i.e., CD95 dim and CD95bright (Böhler et al. 2001). We had shown in the past by magnetic bead isolation and 3-color flow cytometry (Böhler et al. 1997) and by 4color flow cytometry (Böhler et al. 2001) that the cell populations constituting the CD95 dim and the CD95 bright peak of $\mathrm{CD}^{+}{ }^{+} \mathrm{T}$-cells correspond to resting naïve and activated memory cells, respectively. We therefore performed a second study consisting in a direct comparison of CD95 expression levels on T-cells in peripheral blood of healthy adults in Burkina Faso and healthy subjects living in Germany. Our results indicate that differences in the dynamics of T-cell maturation as well as in levels of T-cell activation between Burkina Faso and Germany may be caused by differences in the exposure to Plasmodium falciparum. 


\section{MATERIAL}

Nouna is situated in North West Burkina Faso near the Malian border. Malaria transmission is high during the rainy season between July and November and very little transmission occurs at other times of the year (Müller et al. 2001). Approximately 6 months after the malaria season in May and June 2005 peripheral blood from healthy male and female blood donors was screened for the presence of PfMSP-1 -specific CD4 ${ }^{+}$ lymphocytes during a blood donation campaign in Nouna. The study was part of a population-based study which was undertaken to generate site- and gender-specific reference values for immunohematological parameters in healthy adults. It was approved by the Institutional Ethics Committees of the University of Heidelberg, Germany, and of the Nouna Health Research Centre, Burkina Faso (Klose et al. 2007).

All donors received a clinical examination and all blood samples were tested for infection with HIV (Determine and Genie II, Abbott Laboratories, Wiesbaden, Germany), HBV (Bioline HBsAg Rapid Test Kit, Standard Diagnostics, Kyonggi-Do, Korea) and syphilis (RPR 100, Newmarket Laboratories, Suffolk, UK). In 17 healthy donors (5 male and 12 female) with a median age of 32 years (range, 17 to 43 ) the frequency of PfMSP-1-specific CD4 ${ }^{+}$lymphocytes was assessed. All participants were local residents with lifelong exposure to Plasmodium falciparum not showing clinical signs of acute malaria. During preliminary experiments on peripheral blood from 4 healthy adults in Heidelberg no PfMSP-1-specific $\mathrm{CD}^{+}$lymphocytes had been detected.

Participants of the follow-up study were recruited between September 2008 and February 2009 from students and employees at the Medical Faculty of the University of Heidelberg in Germany (Heidelberg, $\mathrm{n}=20$ ), the Centre Hôpitalier Universitaire Yalgado Ouedraogo (CHUYO, Ouagadougou, $n=20$ ), and the Centre de Recherche en Santé de Nouna (CRSN, Nouna, $n=20$ ) in Burkina Faso. All subjects had a negative HIV test and no clinical signs of illness. Both the national ethics committee in Burkina Faso and the institutional ethics committee at the University of Heidelberg had approved the study protocol. CHUYO is situated in the urban area of Ouagadougou, the capital city of Burkina Faso, West-Africa.

\section{Methods and Statistics}

Samples from Heidelberg were analyzed on a standard FACSCalibur flow cytometer (BD Biosciences, San Jose, CA, USA) equipped with two laser sources, samples from Ouagadougou on a FACSCalibur (BD Biosciences) with only one laser source, and samples from Nouna on a standard single laser FACScan flow cytometer (BD Biosciences). CaliBrite beads (BD Biosciences) were used to set the instrument on a regular basis. Instrument settings were controlled longitudinally and remained constant during the study. Data acquisition for immunophenotyping peripheral blood Tcells was stopped manually when at least 10,000 events were counted in the predefined gate. Data acquisition for the lymphocyte activation assay was not stopped manually; instead, usually, the whole blood sample was acquired in order to increase the amount of analyzable CD4 ${ }^{+}$T-cells (see below). List mode data from all samples were analyzed using the CellQuest Pro software version 5.2 (BD Biosciences).

$\mathrm{CD}^{+}$and $\mathrm{CD}^{+}$naïve and memory lymphocyte subsets were assessed with anti-CD4- or anti-CD8PerCP, anti-CD45RA-FITC and anti-CCR7-PE conjugated monoclonal antibodies as described (Böhler et al. 2007). In order to allow pooled analysis of list mode data obtained on different flow cytometers in the three different study sites, a pattern recognition approach based on the recognition of the cell population clearly identifiable as CD45RA bright CCR7pos naïve T-cells (Sallusto et al. 1999) was used to define the position of the quadrant marker distinguishing different T-cell maturation phenotypes. Compared to our original analysis (Böhler et al. 2007), this approach led to an overestimation of the CD45RA low CCR7pos central memory subpopulation and an underestimation of CD45RA bright CCR7neg effector memory cells, but avoided a fixed setting of the border between CD45RA low and CD45RA bright or between CCR7neg and CCR7pos cells, which would be influenced by differences in FCM settings (e.g., different photomultiplier voltages). The proportion of naïve T-cells was not affected by the differences between both methods of analyzing list mode data.

T-cell activation was determined with anti-CD95PE, anti-CD3-PerCP and anti-CD4-FITC to assess the expression of CD95 on CD4 ${ }^{+}$T-cells, and anti-CD38PE, anti-CD3-PerCP and anti-CD8-FITC to assess the expression of CD38 on $\mathrm{CD}^{+}{ }^{+}$T-cells (Fig. 1). The autofluorescence of an unstained lymphocyte sample of each subject was used as determinator of the marker threshold for $\mathrm{CD} 5^{+}$or $\mathrm{CD} 38^{+}$cells in the histogram plot. Previous experiments had shown that unstained samples and samples incubated with PE-conjugated highly purified isotype control antibodies (BD Biosciences) had identical fluorescence intensities in the FL-2 histogram curves, allowing us to skip isotype control antibodies completely. The marker indicating positivity was set in order to include less than $2 \%$ of unstained lymphocytes.

For determination of the median fluorescence intensity (MFI) of CD95 and CD38 on T-cells, specific T-cell subpopulations were identified by histogram markers as shown in Fig. 1. CD95-expression on human CD4 ${ }^{+}$T-cells was assessed as described, i.e., analyzing CD95 dim and CD95 bright T-cell subpopulations separately (Böhler et al. 2001). The expression of CD38 on $\mathrm{CD}^{+}{ }^{+}$T-cells was characterized by a single unimodal distribution curve in the histogram (Onlamoon et al. 2005). The histogram marker was set to include the CD38 bright cell population which has been shown to be of potential clinical interest (Tuaillon et al. 2009). The QuantiBrite test kit (BD Biosciences) was used in all experiments to convert MFI values into antibody-binding capacity (ABC) per cell according to the instructions of the manufacturer. Since calibration curves were generated on each instrument at each site separately using the same batch of QuantiBrite beads, the resulting numerical $\mathrm{ABC}$ values were not influenced by the different FCM settings. 

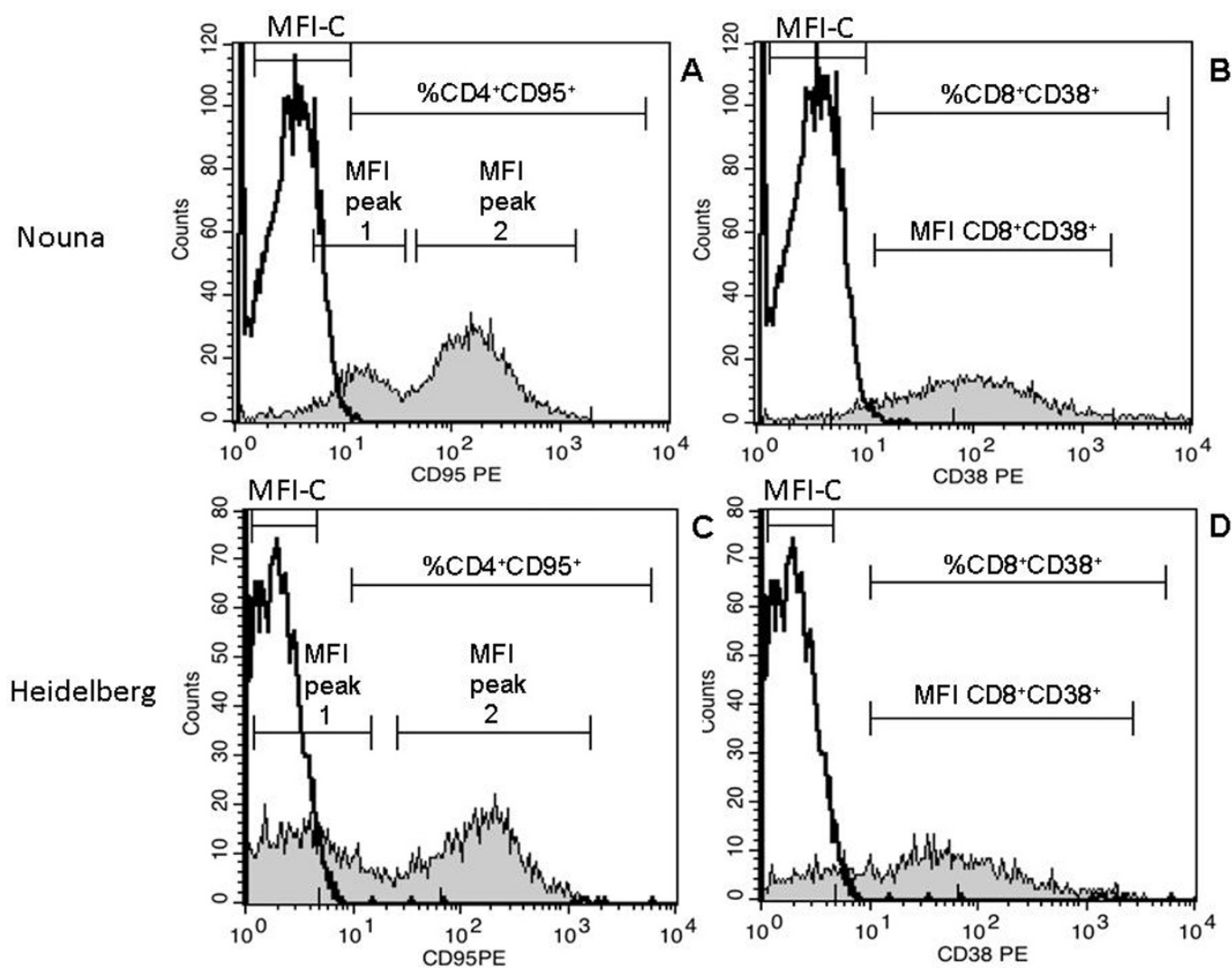

Fig. 1. Assessment of T-cell activation in healthy adults living in Nouna, Burkina Faso (A and B) or Heidelberg, Germany (C and D). Blood samples were stained with anti-CD3-PerCP, anti-CD4-FITC, and anti-CD95-PE (A and C) or anti-CD3-PerCP, anti-CD8-FITC, and anti-CD38-PE (B and D). CD3 ${ }^{+}$lymphocytes were identified as having low side-scatter characteristics (SSC-Height) with a high staining intensity in the FL3 channel (CD3-PerCP). Panel A and C: Expression of CD95 on CD4+ Tcells showed two distinct populations with different CD95 expression levels (peak $1=$ CD4 ${ }^{+}$CD95 ${ }^{\mathrm{dim}}$, peak $2=\mathrm{CD}^{+}$ CD95 bright). Panel B and D: Expression of CD38 on CD ${ }^{+}$T-cells was characterized by a single peak on a broad distribution curve of single cell fluorescence intensities. In each histogram plot a marker spanning the region beyond the unstained control signal was used to determine the percentage of marker-positive cells. The median fluorescence intensity (MFI) of each peak representing a specific cell population as well as the median autofluorescence intensity of unstained control cells (MFI-C) was determined using a specific histogram marker positioned over the histogram curve of the population of interest.

The ex vivo short term lymphocyte activation assay was performed essentially as described (Böhler et al. 2009). Peripheral blood lymphocytes were stimulated with full length PfMSP-1 (Kauth CM et al. 2003) at a concentration of $50 \mu \mathrm{g} / \mathrm{ml}$ and $\mathrm{CD} 4^{+}$lymphocytes producing IFN- $\gamma$, interleukin-2 (IL-2), or tumor necrosis factor-alpha (TNF- $\alpha$ ) were quantified using immunophenotyping and three-colour flow cytometry (Fig. 2). The superantigen Staphylococcal Enterotoxin B (SEB; Sigma-Aldrich, St. Louis, MO, USA) was used at a concentration of $5 \mu \mathrm{g} / \mathrm{ml}$ as a positive control to ensure responsiveness of peripheral blood $\mathrm{T}$ cells. Cells were stimulated for 9 hours at $37^{\circ} \mathrm{C}$, during the last 4 hours the intracellular secretion inhibitor Brefeldin A (BD Biosciences) was added at a concentration of $10 \mu \mathrm{g} / \mathrm{ml}$. A negative control (cells and co-stimulatory antibodies against CD28 and $\mathrm{CD} 49 \mathrm{~d}$, both from BD Biosciences) was included to determine spontaneous production of cytokines.

The statistical significance of the difference between the number of cytokine-producing $\mathrm{CD} 4^{+}$lymphocytes after antigen stimulation and the corre- sponding unstimulated control was tested using the following calculation:

$\mathrm{N}=2 * \mathrm{p}_{\mathrm{av}} *\left(1-\mathrm{p}_{\mathrm{av}}\right) * 8,6 / \Delta^{2}$,

where $\Delta^{2}=\left(\%\right.$ cytokine specific CD $4^{+}$lymphocytes in unstimulated control $) / 100-(\%$ cytokine specific $\mathrm{CD}^{+}$lymphocytes in antigen stimulation $) / 100, \mathrm{p}_{\mathrm{av}}=$ ( $\%$ cytokine specific $\mathrm{CD}^{+}$lymphocytes in unstimulated control $) / 100+\left(\%\right.$ cytokine specific $\mathrm{CD}^{+}$lymphocytes antigen stimulation)/100)/2, and $\mathrm{N}$ is the necessary number of acquired cells needed for a statistical significance of $\mathrm{p}<0,05$ with a statistical power of $90 \%$. If the number of acquired $\mathrm{CD}^{+}$lymphocytes was higher than $\mathrm{N}$, the cytokine production was considered positive.

Mean values, percentiles and standard deviations were calculated for each variable using the GraphPad Prism version 5.00 (Graph Pad Inc., San Diego, CA, USA). Differences between subjects from different sites were analyzed using the non-parametric MannWhitney U-test, p-values $<0.05$ indicated statistical significance. 
anti-lgG

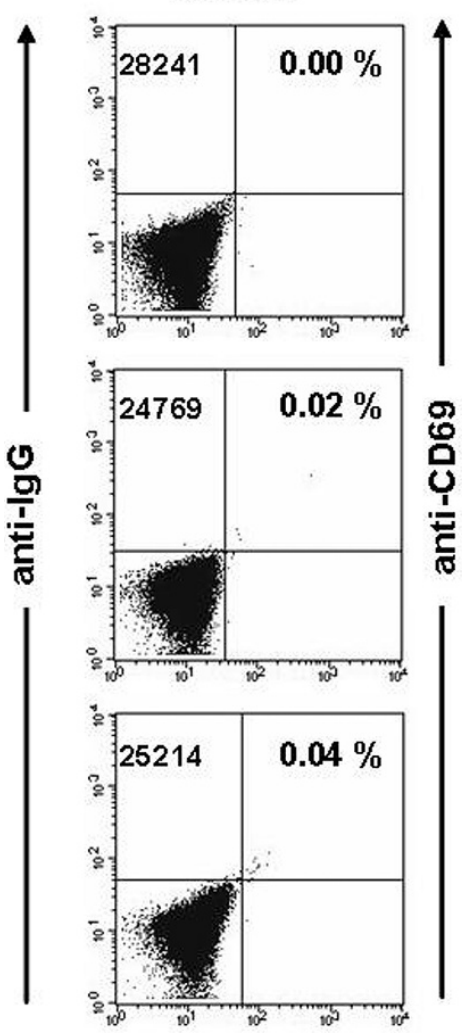

anti-IFN- $\gamma$
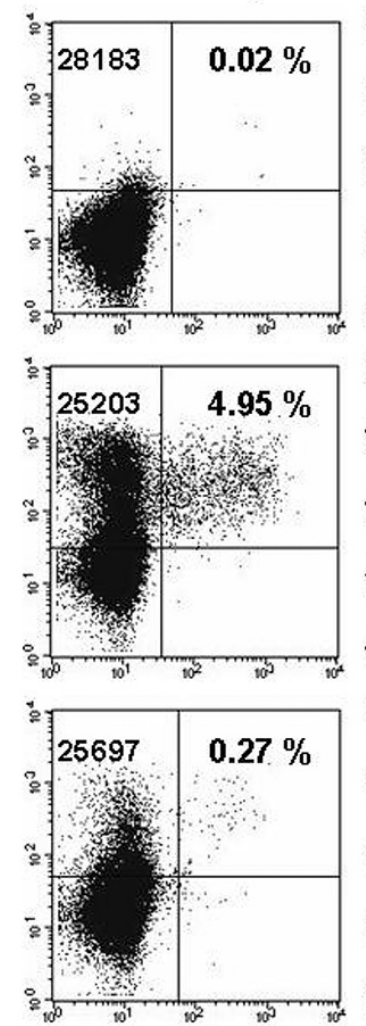

anti-IL-2
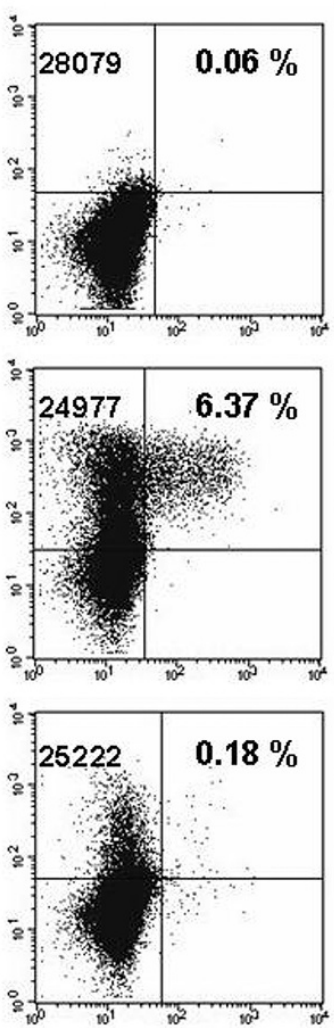

anti-TNF-a

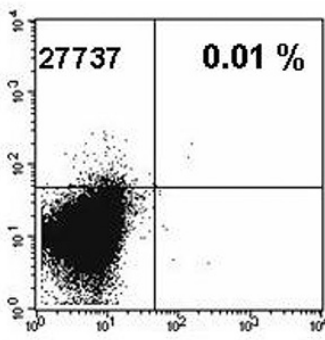

Us

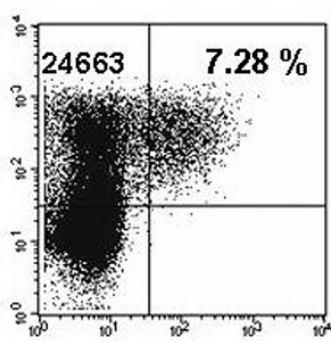

SEB

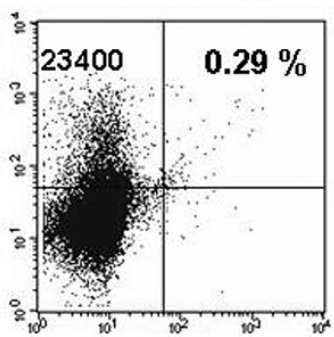

MSP -1

Fig. 2. Detection of Plasmodium falciparum merozoite surface protein-1 (MSP-1)-specific CD4+ ${ }^{+}$-cells in a healthy adult living in Nouna, Burkina Faso using the FastImmune short term lymphocyte activation assay. The columns starting from the left depict results obtained with highly purified IgG isotype control antibodies, or antibodies against interferon gamma (IFN- $\gamma$ ), interleukin-2 (IL-2), and tumor necrosis factor-alpha (TNF- $\alpha$ ). The upper row shows the unstimulated control sample (US), the middle row the positive control sample stimulated with Staphylococcal Enerotoxin B (SEB) and the lower row the sample stimulated with MSP-1. In the upper left quadrant of each dot plot the number of acquired events in the CD4 ${ }^{+}$lymphocyte gate is indicated. In the upper right quadrant the percentage of cytokine-producing cells is shown.

Table 1. Cytokines produced upon ex vivo stimulation with Plasmodium falciparum merozoite surface protein-1 (PfMSP-1) by $\mathrm{CD}^{+}{ }^{+}$lymphocytes in healthy adults living in Nouna, Burkina Faso. Data are shown as per cent of total CD4 ${ }^{+}$cells in the lymphocyte gate. In 4 healthy controls from Heidelberg, Germany, no PfMSP-1-specific CD4+ lymphocytes were detected (data not shown). Abbreviations: n.s. = not significant.

\begin{tabular}{lccc}
\hline Identification No. & Interferon- $\boldsymbol{\gamma}$ & Interleukin-2 & Tumor necrosis factor $\boldsymbol{\alpha}$ \\
\hline CTRL21 & 0.14 & n.s. & 0.06 \\
CTRL23 & n.s. & n.s. & n.s. \\
CTRL33 & 0.16 & 0.09 & 0.19 \\
CTRL36 & n.s. & n.s. & n.s. \\
CTRL37 & 0.14 & n.s. & 0.12 \\
CTRL38 & 0.17 & 0.04 & 0.07 \\
CTRL41 & 0.31 & 0.23 & 0.35 \\
CTRL53 & 0.05 & n.s. & n.s. \\
CTRL55 & 0.14 & 0.07 \\
CTRL56 & 0.34 & n.s. & 0.15 \\
CTRL57 & 0.14 & 0.10 & 0.10 \\
CTRL60 & 0.24 & n.s. & n.s. \\
CTRL61 & 0.09 & n.s. & n.s. \\
CTRL62 & 0.12 & n.s. & 0.39 \\
CTRL65 & 0.77 & n.s. & n.s. \\
CTRL66 & 0.06 & 0.14 & n.s. \\
CTRL67 & n.s. & 0.12 \\
\hline
\end{tabular}




\section{RESULTS}

Among 17 healthy HIV-1-negative adults, 14 responded to PfMSP-1 producing at least one of the measured cytokines ( IFN- $\gamma$, IL-2, TNF- $\alpha$; see Table 1). Of the 14 healthy controls who showed a significant response to PfMSP-1, seven produced all three cytokines. Three subjects produced IFN- $\gamma$ and TNF- $\alpha, 4$ subjects IFN- $\gamma$ alone. Single production of IL-2 or TNF- $\alpha$ could not be detected upon stimulation with PfMSP-1. The median percentage of PfMSP-1-specific cytokine-positive $\mathrm{CD}^{+}{ }^{+}$lymphocytes was $0.21 \%$ (range, 0.06 to $0.77 \%$ ) for IFN- $\gamma$, $0.16 \%$ (0.06 to $0.39 \%$ ) for TNF- $\alpha$ and $0.14 \%$ (0.04 to $0.26 \%)$ for IL-2. The percentage of PfMSP-1-specific IFN- $\gamma^{+}$CD $4^{+}$lymphocytes was higher in healthy controls producing all three cytokines (range, 0.16 to $0,77 \%)$ than in those with single production of IFN- $\gamma$ (range, 0.05 to $0.14 \%$ ).

Compared to Germans, Burkinabé showed markedly lower proportions of $\mathrm{CCR}^{+} \mathrm{CD}^{+} 5 \mathrm{RA}^{+}$ naïve $\mathrm{CD}^{+}{ }^{+}$cells. No such differences were seen in the $\mathrm{CD}^{+}{ }^{+} \mathrm{T}$-cell compartment (Table 2). There was a tendency towards higher frequencies of $\mathrm{CD}^{+} 5^{+}$ $\mathrm{CD}^{+}{ }^{+}$T-cells and of $\mathrm{CD}^{+} 8^{+} \mathrm{CD}^{+}$T-cells in Burkinabé compared to Germans (Table 2). The median $\mathrm{ABC}$ of $\mathrm{CD}^{+} \mathrm{CD} 95^{\mathrm{dim}}$ cells in Burkinabé was more than twice the value observed in Germans (263 vs. $108, \mathrm{p}<0.0001)$. In contrast, no significant differences between both groups were seen regarding the median $\mathrm{ABC}$ levels of CD95 on $\mathrm{CD} 4^{+}$CD95 bright memory T-cells or of CD38 on CD38bright $\mathrm{CD}^{+}{ }^{+} \mathrm{T}$ cells.

\section{DISCUSSION}

Short-term stimulation of peripheral blood lymphocytes with the malaria antigen PfMSP-1 allowed us to detect significant numbers of Pf MSP-1-specific CD4 ${ }^{+}$ lymphocytes in healthy HIV-1-negative blood donors in Nouna, Burkina Faso, but not in Heidelberg, Germany. Fourteen of 17 healthy blood donors in Nouna $(82 \%)$ harboured cytokine producing PfMSP-1-specific $\mathrm{CD}^{+}$lymphocytes in their peripheral blood - a number quite similar to the $80 \%$ prevalence of antibodies against PfMSP-1 observed in the local population (Coulibaly B, unpublished results). T-cell memory against Plasmodium falciparum is thus detectable for at least 6 months after the rainy season, i.e., after the period of high exposure to the parasite.

Naturally acquired T-cell responses to Plasmodium falciparum may shape the expression pattern of activation markers on peripheral blood CD4 ${ }^{+}$T-cells from healthy adults in different ways. Direct involvement in the cellular immune response via T-cell receptor activation may lead to recruitment of naïve $\mathrm{CD} 4^{+} \mathrm{T}$-cells into the effector memory or the central memory pool, thus increasing the percentage of $\mathrm{CD} 4^{+} \mathrm{CD} 95^{\text {bright }} \mathrm{T}$ cells and causing a decrease in the percentage of $\mathrm{CCR}^{+}{ }^{+} \mathrm{CD} 45 \mathrm{RA}^{+}$cells. Bystander activation of naïve $\mathrm{CD}^{+}{ }^{+} \mathrm{T}$-cells due to intermittent high production of IFN- $\gamma$ by PfMSP-1-specific CD4 ${ }^{+}$lymphocytes may increase expression levels of CD95 especially on CD ${ }^{+}$CD $95^{\text {dim }}$ bystander T-cells. When comparing healthy adults in Burkina Faso and Germany, all these parameters were significantly different between both groups. Our findings therefore indicate that naïve

Table 2. Comparison of clinical and immunological parameters between healthy adults in Burkina Faso and Germany. If not otherwise indicated, median values with $10^{\text {th }}$ and $90^{\text {th }}$ percentiles in parentheses are shown. The Mann-Whitney U-test was used to compare groups. Abbreviations: $\mathrm{ABC}=$ Antibody binding capacity, $\mathrm{AU}=$ arbitrary units.

\begin{tabular}{|c|c|c|c|}
\hline & Germany & Burkina Faso & $p$ \\
\hline $\mathrm{n}=$ & 20 & 40 & \\
\hline Female $[\mathrm{n}=]$ & $13(65 \%)$ & $18(45 \%)$ & - \\
\hline Age [median, range] & $28(23-38)$ & $27(19-37)$ & 0.68 \\
\hline \multicolumn{4}{|l|}{ Naïve CD4 ${ }^{+}$lymphocytes } \\
\hline $\mathrm{CD} 45^{\text {bright }} \mathrm{CCR} 7^{+}\left[\%\right.$ of $\mathrm{CD} 4^{+}$lymphocytes $]$ & $38(16-60)$ & $22(3-48)$ & $<0.0001$ \\
\hline \multicolumn{4}{|l|}{$\mathrm{CD}^{+} \mathrm{T}$-cell activation } \\
\hline $\mathrm{CD}^{2} 5^{+}\left[\%\right.$ of $\mathrm{CD} 4^{+} \mathrm{T}$-cells $]$ & $72(57-100)$ & $84(50-97)$ & 0.002 \\
\hline CD95-ABC of CD4 ${ }^{+} \mathrm{CD} 95^{\text {dim }}$ T-cells $[\mathrm{AU}]$ & $108(65-619)$ & $263(196-686)$ & $<0.0001$ \\
\hline $\mathrm{CD} 95-\mathrm{ABC}$ of $\mathrm{CD} 4^{+} \mathrm{CD} 95^{\text {bright }}$-cells $[\mathrm{AU}]$ & $2996(1655-5331)$ & $3316(1474-5285)$ & 0.05 \\
\hline \multicolumn{4}{|l|}{ Naïve $\mathrm{CD}^{+}$lymphocytes } \\
\hline $\mathrm{CD} 45^{\text {bright }} \mathrm{CCR}^{+}\left[\%\right.$ of $\mathrm{CD} 8^{+}$lymphocytes $]$ & $26(6-53)$ & $23(5-52)$ & 0.56 \\
\hline \multicolumn{4}{|l|}{$\mathrm{CD}^{+} \mathrm{T}$-cell activation } \\
\hline $\mathrm{CD}^{2} 8^{+}\left[\%\right.$ of $\mathrm{CD} 8^{+} \mathrm{T}$-cells $]$ & $67(56-97)$ & $77(35-99)$ & 0.03 \\
\hline $\mathrm{CD} 38-\mathrm{ABC}$ of $\mathrm{CD} 8^{+} \mathrm{CD} 38^{+} \mathrm{T}$-cells $[\mathrm{AU}]$ & $1384(440-3270)$ & $1560(866-2450)$ & 0.33 \\
\hline
\end{tabular}


$\mathrm{CD}^{+}{ }^{+} \mathrm{T}$-cells are more activated in healthy adult Burkinabé than in Germans. Differences in the exposure to Plasmodium falciparum are the most likely explanation for this phenomenon.

Skewed maturation and increased activation of peripheral blood T-cells could also be caused by exposure to other infectious diseases. We had observed high prevalences of, e.g., CMV and HBV in the study area (Collenberg et al. 2006). However, T-cell responses to viral infection would be expected to involve primarily the $\mathrm{CD}^{+}$T-cell compartment (Miles et al. 2007). The differences in markers of $\mathrm{CD}^{+}{ }^{+}$-cell maturation and activation between healthy adults in Burkina Faso and Germany were characterized only by a slightly higher percentage of $\mathrm{CD} 38^{+} \mathrm{CD} 8^{+} \mathrm{T}$-cells in Burkinabé. Differences in the exposure to viral infections are therefore an unlikely cause of the deviations observed in the CD4 ${ }^{+}$T-cell compartment in these individuals.

We had previously shown that elevated CD95 expression levels on $\mathrm{CD}^{+}{ }^{+} \mathrm{CD} 95 \mathrm{dim}$ T-cells in HIV-1-infected children and adolescents were not necessarily leading to increased CD95-induced apoptosis of these cells in vitro (Böhler et al. 1999). It is not known, whether increased CD95 expression alters other functional T-cell properties. The CD95 signaling cascade has pleiotropic effects on these cells. While high signal intensities may silence T-cell receptor-induced activation (anergy) or cause activation-induced cell death (apoptosis), low signal intensities especially in resting T-cells may exert co-stimulatory effects (Paulsen and Janssen, 2011). Stronger early IFN- $\gamma$ responses against Plasmodium falciparum have been correlated with lower susceptibility to parasitemia in an interethnic comparison in Mali (McCall et al. 2010). The molecular mechanism which mediates this effect has not yet been discovered. The IFN- $\gamma$-induced increase in expression levels of CD95 on $\mathrm{CD}^{+}$lymphocytes observed in our study may contribute to this effect by lowering the activation threshold of resting naive CD4+ T-cells.

Acknowledgements: We are grateful to all volunteers in Ouagadougou, Nouna, and Heidelberg. Thanks are due to Hermann Bujard for providing recombinant PfMSP-1, Annette Kapaun for help with recruitment of volunteers for developing the ex vivo short term lymphocyte activation assay in Heidelberg, and to Jean Ganamé for help with recruitment of healthy controls in Nouna. This study was supported by a grant from the Deutsche Forschungsgemeinschaft (SFB 544, project A6) and by stipends from Deutscher Akademischer Austauschdienst (DAAD).

\section{REFERENCES}

Achtman AH, Bull PC, Stephens R, Langhorne J. Longevity of the immune response and memory to blood-stage malaria infection. Curr Top Microbiol Immunol. 2005; 297:71-102. Review. PubMed PMID: 16265903.

Böhler T, Bäumler C, Herr I, Groll A, Kurz M, Debatin KM. Activation of the CD95 system increases with disease progression in human immunodeficiency virus type 1 -infected children and adolescents. Pediatr Infect Dis J. 1997 Aug; 16(8):754-9. PubMed PMID: 9271036.

Böhler T, Walcher J, Hölzl-Wenig G, Geiss M, Buchholz B, Linde R, Debatin KM. Early effects of antiretroviral com- bination therapy on activation, apoptosis and regeneration of $\mathrm{T}$ cells in HIV-1-infected children and adolescents. AIDS. 1999 May 7;13(7):779-89. PubMed PMID: 10357376.

Böhler T, Mrosek V, Müller K, Schnitzler P, Hartmann M, Ouedraogo T, Coulibaly B, Sié A, Bartonova V, Tebit DM, Kräusslich HG. Cross-clade recognition of HIV-1 CAp24 by $\mathrm{CD}^{+}{ }^{+} \mathrm{T}$ cells in HIV-1-infected individuals in Burkina Faso and Germany. Open AIDS J. 2009 Jan 23; 3:4-7. PubMed PMID: 19554213; PubMed Central PMCID: PMC2701271.

Böhler T, von Au M, Klose N, Müller K, Coulibaly B, Nauwelaers F, Spengler HP, Kynast-Wolf G, Kräusslich HG. Evaluation of a simplified dual-platform flow cytometric method for measurement of lymphocyte subsets and T-cell maturation phenotypes in the population of Nouna, Burkina Faso. Clin Vaccine Immunol. 2007 Jun; 14(6):775-81. Epub 2007 Apr 18. PubMed PMID: 17442847; PubMed Central PMCID: PMC1951080.

Böhler T, Wintergerst U, Linde R, Belohradsky BH, Debatin KM. CD95 (APO-1/Fas) expression on naive CD4(+) T cells increases with disease progression in HIV-infected children and adolescents: effect of highly active antiretroviral therapy (HAART). Pediatr Res. 2001 Jan; 49(1):10110. PubMed PMID: 11134499.

Clerici M, Butto S, Lukwiya M, Saresella M, Declich S, Trabattoni D, Pastori C, Piconi S, Fracasso C, Fabiani M, Ferrante P, Rizzardini G, Lopalco L. Immune activation in africa is environmentally-driven and is associated with upregulation of CCR5. Italian-Ugandan AIDS Project. AIDS. 2000 Sep 29; 14(14):2083-92. PubMed PMID: 11061648.

Collenberg E, Ouedraogo T, Ganamé J, Fickenscher H, Kynast-Wolf G, Becher H, Kouyaté B, Kräusslich HG, Sangaré L, Tebit DM. Seroprevalence of six different viruses among pregnant women and blood donors in rural and urban Burkina Faso: A comparative analysis. J Med Virol. 2006 May;78(5):683-92. PubMed PMID: 16555290.

Holder AA. The precursor to major merozoite surface antigens: structure and role in immunity. Prog Allergy. 1988;41:72-97. Review. PubMed PMID: 3043424.

Kauth CW, Epp C, Bujard H, Lutz R. The merozoite surface protein 1 complex of human malaria parasite Plasmodium falciparum: interactions and arrangements of subunits. J Biol Chem. 2003 Jun 20;278(25):22257-64. Epub 2003 Mar 24. PubMed PMID: 12654909.

Klose N, Coulibaly B, Tebit DM, Nauwelaers F, Spengler HP, Kynast-Wolf G, Kouyaté B, Kräusslich HG, Böhler $\mathrm{T}$. Immunohematological reference values for healthy adults in Burkina Faso. Clin Vaccine Immunol. 2007 Jun;14(6):782-4. Epub 2007 Apr 18. PubMed PMID: 17442846; PubMed Central PMCID: PMC1951086.

McCall MB, Sauerwein RW. Interferon- $\gamma$-central mediator of protective immune responses against the pre-erythrocytic and blood stage of malaria. J Leukoc Biol. 2010 Dec;88(6):1131-43. Epub 2010 Jul 7. Review. PubMed PMID: 20610802.

McCall MB, Hopman J, Daou M, Maiga B, Dara V, Ploemen I, Nganou-Makamdop K, Niangaly A, Tolo Y, Arama C, Bousema JT, van der Meer JW, van der Ven AJ, TroyeBlomberg M, Dolo A, Doumbo OK, Sauerwein RW. Early interferon-gamma response against Plasmodium falciparum correlates with interethnic differences in susceptibility to parasitemia between sympatric Fulani and Dogon in Mali. J Infect Dis. 2010 Jan 1;201(1):142-52. PubMed PMID: 19929378.

Miles DJ, van der Sande M, Jeffries D, Kaye S, Ismaili J, Ojuola O, Sanneh M, Touray ES, Waight P, RowlandJones S, Whittle H, Marchant A. Cytomegalovirus infection in Gambian infants leads to profound CD8 T-cell differentiation. J Virol. 2007 Jun;81(11):5766-76. Epub 
2007 Mar 21. PubMed PMID: 17376923; PubMed Central PMCID: PMC1900274.

Müllbacher A, Lobigs M, Hla RT, Tran T, Stehle T, Simon MM. Antigen-dependent release of IFN-gamma by cytotoxic T cells up-regulates Fas on target cells and facilitates exocytosis-independent specific target cell lysis. J Immunol. 2002 Jul 1;169(1):145-50. PubMed PMID: 12077239.

Müller O, Becher $\mathrm{H}$, van Zweeden AB, Ye Y, Diallo DA, Konate AT, Gbangou A, Kouyate B, Garenne M. Effect of zinc supplementation on malaria and other causes of morbidity in west African children: randomised double blind placebo controlled trial. BMJ. 2001 Jun 30;322(7302):1567. PubMed PMID: 11431296; PubMed Central PMCID: PMC33513.

Onlamoon N, Tabprasit S, Suwanagool S, Louisirirotchanakul S, Ansari AA,Pattanapanyasat K. Studies on the potential use of CD38 expression as a marker for the efficacy of anti-retroviral therapy in HIV-1-infected patients in Thailand. Virology. 2005 Oct 25;341(2):238-47. Epub 2005 Aug 11. PubMed PMID: 16099011.

Paulsen M, Janssen O. Pro- and anti-apoptotic CD95 signaling in $\mathrm{T}$ cells. Cell Commun Signal. 2011 Apr 8;9:7. PubMed PMID: 21477291; PubMed Central PMCID: PMC3090738.

Sallusto F, Lenig D, Förster R, Lipp M, Lanzavecchia A. Two subsets of memory $\mathrm{T}$ lymphocytes with distinct homing potentials and effector functions. Nature. 1999 Oct 14; 401(6754):708-12. PubMed PMID: 10537110.

Saule P, Trauet J, Dutriez V, Lekeux V, Dessaint JP, Labalette M. Accumulation of memory $T$ cells from childhood to old age: central and effector memory cells in $\mathrm{CD} 4(+)$ versus effector memory and terminally differentiated memory cells in CD8(+) compartment. Mech Ageing Dev. 2006 Mar;127(3):274-81. Epub 2005 Dec 13. PubMed PMID: 16352331.
Struik SS, Riley EM. Does malaria suffer from lack of memory? Immunol Rev. 2004 Oct;201:268-90. Review. PubMed PMID: 15361247.

Tuaillon E, Al Tabaa Y, Baillat V, Segondy M, Picot MC, Reynes J, Vendrell JP. Close association of CD $8^{+} / \mathrm{CD} 38$ bright with HIV-1 replication and complex relationship with CD4+ ${ }^{+}$T-cell count. Cytometry B Clin Cytom. 2009 Jul;76(4):249-60. PubMed PMID: 19072838.

Received: June 21, 2011 / Accepted: July 8, 2011

Address for correspondence:

PD Dr. Thomas Böhler

Prof. Dr. Hans-Georg Kräusslich

Department of Infectious Diseases - Virology

University of Heidelberg

INF324

69120 Heidelberg

Germany.

Phone: +49-6221565002.

Fax: +49-6221565003

Emails:

thomas.boehler@uni-heidelberg.de

Hans-Georg_Kraeusslich@med.uni-heidelberg.de 